\title{
Lateral
}

JOURNAL OFTHE CULTURALSTUDIESASSOCIATION

Saugher Nojan, "Review of Civil Racism: The 1992 Los Angeles Rebellion and The Crisis of Racial Burnout by Lynn Mie Itagaki (University of Minnesota Press)," Lateral 7.2 (2018).

https://doi.org/10.25158/L7.2.17

This content is licensed under a Creative Commons Attribution 4.0 International License. Copyright is retained by authors.

Book Reviews

Issue 7.2 (Fall 2018)

\section{Review of Civil Racism: The 1992 Los Angeles Rebellion and The Crisis of Racial Burnout by Lynn Mie Itagaki (University of Minnesota Press)}

\section{Saugher Nojan}

\begin{abstract}
Lynn Mie Itagaki contributes to cultural and comparative race studies by uncovering the implications of what she calls the 1992 Los Angeles Rebellion-a constellation of events spurned on by the Rodney King verdict-for intersecting groups and communities including women, immigrants, Black, Asians, and Latina/o-Americans. Each chapter provides a different context (family, education, neighborhood) for structures and discourses that perpetuate civil racism, while at the same time illuminating specific acts of resistance and subversion that occur, in each instance, through media, activism, and art. Itagaki's methodology moves beyond critical literary analysis to provide important social commentary and critique that will prove useful to interdisciplinary scholars seeking to learn about racial formations in the neoliberal U.S. context.
\end{abstract}

Civil Racism: The 1992 Los Angeles Rebellion and The Crisis of Racial Burnout by Lynn Mie Itagaki. Minneapolis, MN: University of Minnesota Press, 2016, 336 pp. (paperback) ISBN 978-0-8166-9921-6. US List: \$25.00.

In Civil Racism: The 1992 Los Angeles Rebellion and the Crisis of Racial Burnout, Lynn Mie Itagaki contributes to cultural and comparative race studies by uncovering the implications of what she calls the 1992 Los Angeles Rebellion-a constellation of events spurned on by the Rodney King verdict-for intersecting groups and communities including women, immigrants, Black, Asians, and Latina/o-Americans. Her work presents unique racial concepts that unmask the process of how racism and civil society are intertwined and extended through the US. She looks at the effects of the US both at home and abroad and in the contemporary contexts of post-racialism and colorblindness, as well as archaic forms of racial violence. Itagaki's expertise in critical ethnic studies, women of color feminisms, and 21st century African-American and Asian-American literatures shines through in her theoretically-rich literary and cultural analysis of various social "texts." The analysis of journalism, film, literature, theatre, and other media provide insight into a wide array of issues including but not limited to: civility/incivility, racism, patriarchy, citizenship, American politics and media, militarism, capitalism, neoliberalism, intersectionality, resistance, and solidarity. Itagaki's methodology moves beyond critical literary analysis to provide important social commentary and critique that will prove useful to interdisciplinary scholars seeking to learn about racial formations in the neoliberal US context.

Itagaki's discussion of the 1992 Los Angeles rebellion and the crisis of racial burnout is based on the events surrounding the mass public reception of the videotaped beating of Rodney King, the acquittal of the officers involved, and the uprising that followed. Itagaki draws upon these events to elucidate how civil racism manifests in racialized discourses of 
civility that emerge in contradictory discourses of colorblindness, equal rights and meritocracy. Civil racism appears as a "discourse of racial civility" and is characterized by the "triumph of a politics of civility at the expense of racial equality" (6). Each chapter provides a different context (family, education, neighborhood) for structures and discourses that perpetuate civil racism, while at the same time illuminating specific acts of resistance and subversion that occur, in each instance, through media, activism, and art. The epilogue brings together the implications of civil racism into the current context of the Black Lives Matter movement, demonstrating how discourses of (in)/civility continue to characterize how the state relates to citizens, noncitizens, and acts of dissent. In addition to her main theoretical framework of "civil racism," Itagaki provides significant concepts throughout her text that nuance racialization more broadly.

One strength of this work is how Itagaki skillfully interweaves several theories to provide new insight on racialization. Of these concepts, I will focus on racial pyramidization and the biologization and territorialization of (in)/civility. All of these concepts help us make sense of specific discourses of race and racialization in the context of (in)/civility: how they emerge, how they play out in the realm of politics, and how acts of resistance are portrayed and delegitimized in the media and by the state. Drawing on the frameworks of intersectionality and racialized social systems in the work of Kimberlé Crenshaw, Patricia Hill Collins, Eduardo Bonilla-Silva, and others, Itagaki introduces the concept of racial pyramidization, which disaggregates the experiences of racialized groups along the lines of class, gender, and citizenship, while still understanding them in relation to white supremacy and anti-blackness. Using the figure of a pyramid, Itagaki explains that: "Pyramidization provides another way to imagine civil racism and racial burnout: the triangulation on the faces closest to the viewer obscures the furthest, hidden vertex, a racial erasure for one group that often may be ignored but is still a crucial defining party of the figure" (9). Through pyramidization, Itagaki shows how framing the LA crisis as a largely White/Black, Black/Korean conflict, erases the impact of the crisis on the Latinx community. The Latinx community made up half of all arrests where participants were involved in "looting and mayhem" (104). The state deported hundreds of undocumented migrants in the aftermath as an opportunity to enact retributive violence on this community and delegitimize their solidarity with Blacks challenging state injustices. Since the state cannot easily deport citizens, it elicited public debates on civility in this moment of urban upheaval to confirm that "'have nots' lack the civic virtues that build a democracy and thus deserve to be amputated from it" (88). Thus, through techniques attributable to racial pyramidization, the state reclaims its power as the only institution that can "evaluate justice and adjudicate punishment" (105-6).

Furthermore, the state relies on racist ideologies that biologize civility, culture, and merit in order to blame individuals and communities for their conditions of poverty and violence. Framing the 1992 Rebellion as "riots" and "revenge" for the police beating of Rodney King and the murder of Latasha Harlins enabled the state and the media to characterize participants as innately savage, criminal, and immoral, and deserving of punishment for committing uncivil violence (120). Itagaki extends this framework by demonstrating how the "biologization of civility" (86) operates transnationally in what she terms, "territorialization of incivility" (106). Itagaki explains that mapping incivility onto "non-white, non-citizen" bodies enables the state to enact punishment, not only on these bodies, but also on the countries associated with these bodies, as part of post-Cold War geopolitics and imperialist policies (107). All of these concepts further draw out the importance of thinking from a framework of civil racism to illuminate the scope of the state, conceptions of civility and incivility, and the contradictions in state discourses and actions. 
These concepts, developed here to understand the particular context of the LA rebellions, help illuminate race relations in the neoliberal era and the ways that the state uses discourses of civility to enact violence and delegitimize resistance by people of color working against racism. As a sociologist coming to this work, I found Itagaki's elaboration of civil racism theoretically rich and relevant for many other facets of race relations in the US post-Cold War context. There were times when I would get lost in the details of the social texts that Itagaki was reviewing, but the breadth and depth of her examples did not detract from the book's important contributions. I would have liked to see a section where Itagaki elaborated on how civil racism, as a framework, could be built upon or applied to different state relations that delegitimize dissent, especially in the post-9/11 world. I appreciated Itagaki's careful use and analysis of language. Calling the events that occurred in 1992 a rebellion instead of a riot provides insight into how the rest of her book centers the subversion of people of color in the face of state oppression. Overall, I recommend this book to anyone wanting to learn more about race, intersectionality, citizenship, and critical literary/media analysis.

$\stackrel{\dot{B} B \text { io }}{ }$

\section{Saugher Nojan}

Saugher Nojan is a Ph.D. candidate in the Department of Sociology at University of California, Santa Cruz, with a designated emphasis in Education and Critical Race \& Ethnic Studies. Saugher studies Muslim and Afghan diasporic experiences with regards to education, migration, gendered racialization, Islamophobia and US empire.

\footnotetext{
(c) (7)

This work is licensed under a Creative Commons Attribution 4.0 International (CC BY) License, unless otherwise noted. ISSN 2469-4053
} 